\title{
Research on the Teaching Status and Countermeasures of Econometrics in Newly-Built Local Universities
}

\author{
Huiqing Wang*, Qingfang Su \\ Emerging Economic Formats Research Institute, \\ Shandong Management University, \\ Jinan in Shandong, 250357
}

\begin{abstract}
In the Information Era, as all kinds of data show explosive growth, the demand for mathematical analysis ability of college graduates from all walks of life is increasing. It is one of the teaching objectives of local application-oriented colleges and universities to train students how to apply econometrics to quantitative analysis of economic problems. However, the actual teaching effect of econometrics is not ideal enough, making it difficult for these students to meet the needs of the current society. Based on the teaching practice and descriptive statistical analysis of the questionnaire, this paper analyzes the teaching status quo of econometrics in newly-built local colleges and universities, and puts forward some countermeasures and suggestions to improve the teaching effect.
\end{abstract}

Keywords-applied talents training; Econometrics teaching; newly-built local universities

\section{INTRODUCTION}

Big data covers a broad range of areas, such as enterprises, governments and consumers as well as how to effectively find problems and predict the future. Thus, to train students majoring in economics how to conduct quantitative analysis on economic issues has been increasingly recognized by all sectors of society. Econometrics is a science based on economic theory and supported by data. As a theoretical tool for analyzing economic problems, it uses probabilistic method to conduct quantitative analysis on the relationship between economic variables. Therefore, the importance of improving the teaching effect of econometrics is self-evident.

Due to new characteristics of the Internet economy era, new requirements on the training goal of universities have been proposed. The Party Central Committee and the State Council have adjusted the national talent training strategy accordingly. As can be seen clearly from the document jointly issued by Ministry of Education and the other two ministries in 2015, local colleges and universities should truly turn their schooling thought to training personnel of technology applied type and skill type, and improve social economy coordinated development in service area of schools. Therefore, in recent years, a number of newly-established local universities and colleges mainly aim at cultivating applied talents. The training of applied talents shall be finally realized through school courses ${ }^{[1]}$. However, the actual teaching effect of econometrics

The Doctoral Research Foundation of Shandong Management University sponsored the paper. is not ideal enough ${ }^{[2-4]}$ And in the process of econometrics teaching, how to improve the teaching effect, balance the relationship between theoretical explanation and practical application, and better achieve the goal of cultivating applied talents in local newly-built undergraduate colleges shall be worth our in-depth study. Based on this, this paper combines with teaching practice, and descriptive statistical analysis of questionnaire data, finds the teaching status quo of econometrics in local newly-built undergraduate colleges, and puts forward countermeasures and suggestions so as to improve the teaching effect.

\section{THE TEACHING STATUS OF ECONOMETRICS IN NEWLY-BUILT LOCAL UNIVERSITIES}

In order to obtain an in-depth understanding of students study on econometrics, this paper investigated students majoring in Economics and Financial engineering from Shandong Management University in the form of a questionnaire survey, which specifically involved learning attitude, basic knowledge, learning engagement and other issues $^{[5]}$. A total of 300 questionnaires were randomly distributed, and 280 were recovered and 265 were valid, among which girls accounted for about 2/3; the number of students in Economics: the number of students in financial engineering is about 3:2; there were 83 seniors and 182 juniors, accounting for 31.3 percent and 68.7 percent, respectively. Combining the survey data with the specific teaching practice in our school, we summarize the teaching status of Econometrics in local newly-built undergraduate colleges as follows:

\section{A. Unsound professional faculty and its unreasonable structure}

As can be seen from the teaching staff, with the rapid expansion of its scale, most local colleges and universities have existed the common problem---unsound professional faculty after upgrading, especially the newly established undergraduate colleges and universities that have just undergone the repositioning of discipline layout and the re-setting of professional structure, which will inevitably lead to the lack of specialized teachers. Take the faculty of Economics in our university as an example. In 2015, there were only 3 full-time teachers, and so far there are only 10 . When the econometrics course was first offered in 2017, only one teacher was engaged 
in the teaching of this course. Since then, the courses of econometrics have been offered successively in the majors of financial engineering and International economics and trade, and there are only two professional teachers so far.

Besides, the construction of professional faculty engaged in the teaching of econometrics is not reasonable in terms of age structure, professional title structure, and professional structure and so on. In the case of age structure, young teachers are in the majority, making it lack of curriculum leaders and causing the structure level not reasonable enough. From the perspective of professional title structure, medium-grade professional title occupies the most, and there are few senior professional title teachers. In the case of knowledge structure, there is a general phenomenon that the foundation of economics is good, but that of mathematics and statistics is relatively weak, and there is a serious shortage of "double-professionally-titled" teachers. Newly-built undergraduate colleges and universities pay more attention to practice teaching, therefore, they must focus on the development of "double-professionally-titled" teachers because efforts to improve the teaching level of "double-professionallytitled" teachers is the key to cultivate applied talents ${ }^{\lfloor]}$ However, most of the young econometric teachers are directly engaged in teaching work after graduation, leading to a serious shortage of "double-professionally-titled" teachers in the newly-established local universities. The two teachers engaged in the teaching work of econometrics in our school are both young teachers, including one associate professor and one lecturer, only one with mathematics education background, and only one "double-professionally-titled" teacher.

\section{B. Unreasonable teaching settings and monotonous teaching forms}

Talent cultivation programs in economics major from most of newly-built undergraduate universities are still on the stage of learning and exploring, which is likely to result in unreasonable teaching settings, especially the unreasonable class arrangement of theoretical teaching and practical teaching, and will further lead to the unreasonable arrangement of teaching contents. Theory is the foundation of practical application, and over-compressing theoretical periods will inevitably have a negative impact on the cultivation of students' application ability. In addition, econometrics is mostly a new course offered by newly-established undergraduate colleges. Most of the teachers engaged in the teaching are young teachers, who lack teaching experience, have insufficient overall grasp of its content and always adopt the monotonous teaching form of blackboard writing and PPT. In the fifth semester, econometrics course was set up in economics major of our university. There was an unreasonable phenomenon that it was set at the same time as statistics, one of the prerequisite courses. There were 32 class hours for theoretical teaching and 64 class hours for practical teaching. In the newly revised talent cultivation program, econometrics is reduced to 48 class hours, including 32 class hours in theory and 16 credit hours in practice. Due to a small number of theoretical hours, the teaching content can only focus on the classical econometric theories and methods such as unitary linear regression, multiple linear regression, heteroscedasticity, and autocorrelation, and students will not be able to interpret the results of practical regression.

\section{Insufficient teaching resources and single assessment methods}

Due to the rapid expansion of teaching scale, newly-built local undergraduate colleges and universities are relatively short of fund and teaching resources such as teaching instruments and equipment, laboratories, books and materials which are insufficient and outdated. In order to cultivate students' ability to solve practical economic problems through econometric models, it is necessary to carry out practical teaching in the laboratory, ad make students master how to operate at least one kind of econometric software. The practice teaching of econometrics in most undergraduate universities is not an independent course, and the examination of econometrics is mainly based on closed-book exam, which has great deficiencies in the examination of students' practical ability. There are only two economics laboratories in our school, with less than 100 computers. Fewer books on econometrics in the library have been equipped with, only 18 of which are available for students to borrow and published earlier. The closed-book exam (70\% of the total score) is adopted to mainly assess the students' mastery of theoretical knowledge and exists the lack of assessment of students' practical ability.

\section{Weak foundation and low interest in learning of students}

The enrollment quality of newly-established local undergraduate colleges is generally not high. There are many students majoring in liberal arts in senior high school, and they have poor foundation of prerequisite courses, high fear of difficulties, and low interest in learning and poor learning habits, which result in unsatisfactory learning effect of econometrics. According to the data collected from the questionnaire, $83 \%$ and $74.7 \%$ of the students indicated that they had a general or even lower command of econometric theoretical knowledge and software, respectively. About $60 \%$ of students were liberal arts students in high school. Only about $24 \%$ thought that they had a good command of advanced courses and above, and $53.2 \%$ believed that the poor foundation of advanced courses was the main reason for their failure to master the knowledge of econometrics. The proportion of students who think econometrics is difficult or above is as high as $77 \%$. The proportion of students showing general or even lower interest in learning was $43.4 \%$. Only $35.8 \%$ of the students said that most or all of the assignments were completed independently, and those who could do more preview and review accounted for $6 \%$ and $16.2 \%$ respectively.

\section{SUGGESTIONS ON THE TEACHING REFORM OF ECONOMETRICS IN NEWLY-BUILT LOCAL UNDERGRADUATE COLLEGES}

\section{A. Strengthen the construction of professional teachers,} especially the cultivation of "double-professionally-titled" teachers

The professional faculty of Econometrics major is the basis to realize the training goal of economic professionals and an important factor affecting the teaching quality of courses. First 
of all, the number of professional teachers for econometrics courses should be increased to strengthen the teaching staff and gradually alleviate the shortage of teaching staff in newly-built local universities. Secondly, econometrics is the combination of economic theory, mathematics and statistics, which requires a good foundation in mathematics and economics. However, most teachers engaged in the teaching of econometrics are not equipped with a good foundation in mathematics and economics at the same time. Therefore, the optimization of teachers' knowledge structure should be paid more attention to. Finally, in order to realize the goal---training applied talents in local newly-built undergraduate colleges and universities, course teachers should have corresponding practical experience and ability to use knowledge, and can teach students how to analyze trends of enterprises development through econometric model, as well as how to forecast the future development of enterprises. Therefore, the cultivation and development of the "double-professionally-titled" teachers of econometrics should be paid more attention to.

\section{B. Explore teaching arrangements suitable for students and introduce open online courses}

Econometrics requires relatively complete advanced mathematics and economics as its leading courses, so its teaching time should be arranged after the completion of relevant preparatory courses, namely in the sixth or seventh semester. In the process of teaching, it is necessary to deal with the relationship between the basic and the frontier of teaching content, as well as the relationship between theoretical learning and practical application. In the case of limited class hours, the arrangement of teaching content should be based on the foundation, and the frontier should be appropriately introduced, while giving consideration to practical application. In the process of theory teaching, we should pay more attention to train of thought than derivation. In the Internet era, high-quality resources can be shared on the open online courses sharing platform. Therefore, the introduction of econometrics online open courses can not only supplement the teaching content of our school, but also enrich students' horizon. According to the data of the questionnaire, as many as $83.8 \%$ of the students believed that it is necessary to review the relevant mathematical knowledge before learning the theoretical knowledge of econometrics; $85 \%$ said they did not want to reduce the number of theory classes.; $65 \%$ considered that they wanted to take econometric experiment as an independent course. 89\% thought that the introduction of open online courses would help their learning on econometrics.

\section{Improve teaching resources and enrich assessment methods}

Newly-built local universities should make efforts to improve teaching resources, optimize teaching environment, strengthen laboratory construction, and increase collection of econometric reference books. At the same time, the construction and development of course resources should be strengthened to further enrich the teaching resources of this course, such as teaching programme, case set and item bank, so that teachers and students can effectively use the laboratory and the course website to carry out efficient and flexible teaching and learning. In order to stimulate students' enthusiasm in learning and applying econometrics, and improve their practical ability as well as the ability of applying econometric methods to economic problems' research, courses of econometrics should pay more attention to process assessment and practice assessment. At present, the process assessment (only including attendance and homework completion) accounts for $30 \%$ in most colleges, and most students expect to get good grades in the last review stage. The final exam mainly evaluates the mastery of theoretical knowledge, while practical assessment is often neglected. Therefore, the examination of econometrics course should increase the practical exam, so as to enrich the form of process examination, make students study hard in daily life, strengthen the practicality of theory, and guide students take the initiative to improve attendance and classroom performance. According to the questionnaire data, as many as $70.6 \%$ of the students believed that increasing practice assessment will help improve the study of econometrics.

\section{Enrich classroom teaching methods and stimulate students' interest in learning}

Interest is the best motivation for learning, and whether to mobilize students' interest in learning, has related to the level of teaching effect. Then how to guide students to be interested in the teaching content of econometrics? In the classroom teaching, we should enrich the teaching methods, combine teaching, self-study, discussion, flip, case and other methods, pay attention to inspire students to think actively, increase the interaction with students and timely understand the students' grasp of knowledge, and focus on cultivating students' logical thinking ability and the ability to analyze and solve problems. In the link of practical teaching, the model shall be analyzed and displayed in combination with practical cases, so that students can be clear about the practical value of the model, their initiative and enthusiasm will be stimulated in learning and applying econometrics, and their hands-on ability and the ability to study economic problems by applying econometric methods will be highly improved.

\section{CONCLUSION}

In the Internet information age, data in various forms have been growing rapidly, and both the country and enterprises are in increasing demand for the mathematical analysis ability of college graduates. In recent years, a number of newlyestablished local universities and colleges take cultivating applied talents as the goal, and emphasize on cultivating students' ability to analyze economic problems quantitatively with econometric theories and methods, so as to take this as their competitive characteristics. Based on the teaching practice and descriptive statistical analysis of the questionnaire, this paper considers that the teaching of econometrics in newlybuilt local universities has the following problems: unsound professional faculty and its unreasonable structure; unreasonable teaching settings and monotonous teaching forms; insufficient teaching resources and single assessment methods; weak foundation and low interest in learning of students. Finally, the corresponding countermeasures and suggestions are put forward. 


\section{REFERENCES}

[1] Liu Huanyang, Han Yanlun, Zhang Feng. Thoughts on the cultivation of applied talents in local universities, Journal of LudongUniversity (philosophy and social science edition), 2012, 29(3):71-74.

[2] Zhou Mei. Discussion on econometric teaching reform based on market demand-oriented statistical modeling contest [J]. Educational teaching BBS, 2019, 8:164-165.

[3] Kang Jian. Research on econometrics teaching reform in undergraduate period under the guidance of application [J]. Times economics \& trade, 2008, 29:99-100.
[4] Li Zhanjiang, Liu Yan. Discussion on the teaching reform of econometrics -- aiming at the training target of applied technology talents [J]. Journal of Inner Mongolia agricultural university (social science edition), 2019, 3:1-3.

[5] Ma Yongjun, Cao Yaowen. Factors influencing the teaching effect of "econometrics" [J]. Teaching and educating (higher education BBS), 2019, 3:96-97.

[6] Shi Rong. Research on the team of econometric teachers based on the application of "double teachers" [J]. Economic research guide, 2019, 2:162-163. 